Pathophysiology

of Haemostasis and Thrombosis
Pathophysiol Haemost Thromb 2005;34:48-50

DOI: $10.1159 / 000088548$
Received: March 7, 2005

Accepted after revision: July 7, 2005

\title{
Acute Myocardial Infarction with Lung Cancer during Treatment with Gefitinib: the Possibility of Gefitinib-Induced Thrombosis
}

\author{
K. Yamaguchi S. Kanazawa Y. Kinoshita M. Muramatsu S. Nomura \\ First Department of Internal Medicine, Kansai Medical University, Moriguchi, Osaka, Japan
}

\section{Introduction}

The Iressa (gefitinib) Dose Evaluation in Advanced Lung Cancer (IDEAL) 2 clinical trial indicated a good response rate in Japanese patients [1]. However, Cappuzzo et al. [2] reported that efficacy, toxicity, and symptom outcome in patients with non-small-cell lung cancer (NSCLC) treated with gefitinib do not seem to be related to epidermal growth factor receptor (EGFR) or HER2 expression. Recently, Lynch et al. [3] reported that a subgroup of patients with NSCLC had specific mutations in the EGFR gene, which correlated with clinical responsiveness to gefitinib. However, these findings may not explain the mechanism of gefitinib in many stable cases. The main anticancer mechanism of gefitinib in clinical cases remains unclear. On the other hand, severe adverse effects, including acute lung injury, interstitial pneumonia and alveolar hemorrhage, have been reported in Japan in patients receiving gefitinib $[4,5]$. We describe a case of acute myocardial infarction with lung cancer experienced during treatment with gefitinib, since this may be one of the adverse effects induced by gefitinib.

\section{Case Report}

A 75-year-old female suffering from lung adenocarcinoma underwent right lower lobectomy 4 years previously. One year after the operation, she developed hypertension and diabetes mellitus. She did not suffer from hypercholesterolemia and did not smoke. Further, she had a relapse of lung cancer 1 year previously. The administration of gefitinib was then started. A good response was observed but with a grade 1-2 skin adverse toxicity (table 1, period A). Two months later she complained of severe fatigue, and electrocardiography (ECG) revealed ischemic changes (table 1, period B). She was diagnosed with acute myocardial infarction. Therefore, the administration of gefitinib was halted. On admission day, ECG revealed sinus rhythm with an ST elevation in leads $\mathrm{V}_{1-3}$ and a $\mathrm{T}$ wave inversion in leads $\mathrm{V}_{3-6}$ (fig. 1). However, there were neither changes in ECG findings nor abnormalities in laboratory tests over the next $24 \mathrm{~h}$ (table 1, period C). On the other hand, echocardiographic findings were consistent with a diagnosis of myocardial infarction in the left anterior descending area. After 2 weeks' observation, the administration of gefitinib was restarted under the continued treatment with aspirin (table 1, period D). Following about 2 weeks' administration of gefitinib, a minor response of the lung cancer was observed. An analysis of platelet aggregation, stimulated by ADP or collagen before and after 2 weeks of receiving gefitinib, was performed. Both ADP and collagen-induced aggregations were suppressed before the restart of gefitinib. However, both the aggregations exhibited a tendency towards enhancement after the restart of gefitinib.

\section{Discussion}

We reported here the case of myocardial infarction experienced by a 75-year-old woman during the course of treatment with gefitinib for NSCLC. Gefitinib acts on the EGF pathway and in conjunction with radiation and tumor vasculature localization, endothelial cell damage and thrombosis occur under experimental conditions, and only in the indicated combination [6]. At least to our knowledge, thrombosis or myocardial infarction has not

\begin{tabular}{ll}
\hline KARGER & ( ) 2005 S. Karger AG, Basel \\
Fax +4161306 1234 & $8832 / 05 / 0341-0048 \$ 22.00 / 0$ \\
$\begin{array}{l}\text { E-Mail karger@karger.ch } \\
\text { www.karger.com }\end{array}$ & $\begin{array}{l}\text { Accessible online at: } \\
\text { www.karger.com/pht }\end{array}$
\end{tabular}

Shosaku Nomura

First Department of Internal Medicine, Kansai Medical University

10-15 Fumizono-cho

Moriguchi, Osaka 570-8507 (Japan)

Tel. +81 6992 1001, Fax +81 72532 1113, E-Mail shosaku-n@mbp.ocn.ne.jp 


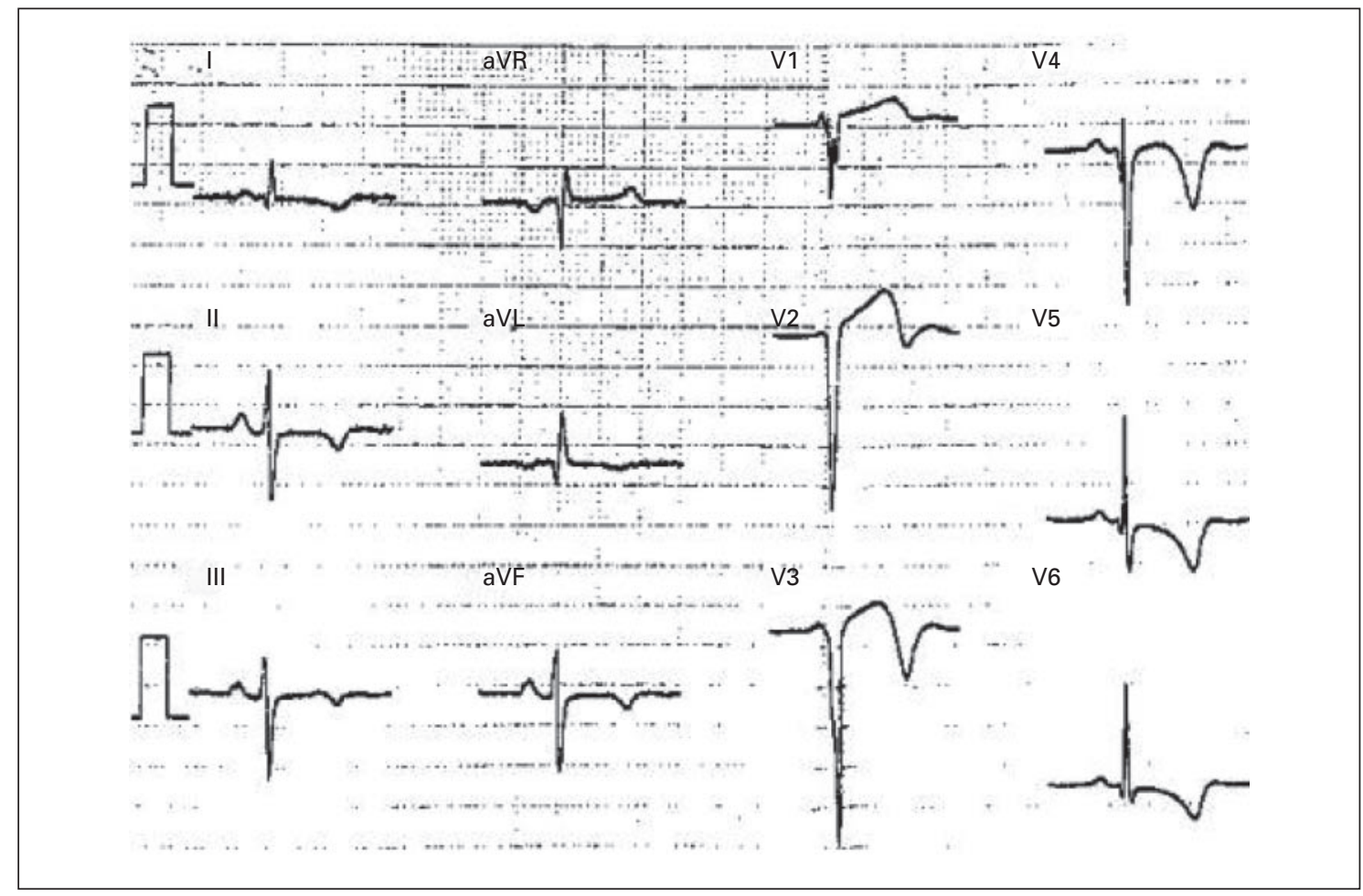

Fig. 1. ECG findings at onset of myocardial infarction. ECG revealed sinus rhythm with an ST elevation in leads $\mathrm{V}_{1-3}$ and a $\mathrm{T}$ wave inversion in leads $\mathrm{V}_{3-6}$.

Table 1. Hematological and biochemical laboratory values

\begin{tabular}{|c|c|c|c|c|c|}
\hline & \multicolumn{4}{|l|}{ Period } & \multirow[t]{2}{*}{ Normal values } \\
\hline & A & $\mathrm{B}$ & $\mathrm{C}$ & $\mathrm{D}$ & \\
\hline \multicolumn{6}{|l|}{ Hematological data } \\
\hline White-cell count, $\mu$ l & 8,200 & 7,000 & 7,900 & 5,200 & $3,000-8,000$ \\
\hline Red-cell count, $\times 10^{4} / \mu 1$ & 402 & 491 & 453 & 418 & $370-510$ \\
\hline Hemoglobin, g/dl & 10.4 & 13.1 & 12.0 & 10.8 & $11.3-15.4$ \\
\hline Platelet count, $\times 10^{4} / \mu 1$ & 16.9 & 14.9 & 17.3 & 34.6 & $14-34$ \\
\hline \multicolumn{6}{|l|}{ Biochemical data } \\
\hline Total protein, g/dl & 7.4 & 7.7 & 6.9 & 6.5 & $6.5-8.0$ \\
\hline Aspartate aminotransferase, U/1 & 19 & 43 & 26 & 21 & $12-31$ \\
\hline Alanine aminotransferase, U/1 & 11 & 16 & 13 & 10 & $6-24$ \\
\hline Lactic acid dehydrogenase, U/1 & 191 & 265 & 208 & 190 & $105-210$ \\
\hline Alkaline phosphatase, U/1 & 298 & 390 & 327 & 279 & $107-323$ \\
\hline Urea nitrogen, $\mathrm{mg} / \mathrm{dl}$ & 33 & 23 & 23 & 30 & $8-20$ \\
\hline Creatinine, $\mathrm{mg} / \mathrm{dl}$ & 1.03 & 0.87 & 0.83 & 0.95 & $0.40-0.80$ \\
\hline Creatinine kinase, U/1 & 36 & NT & 46 & 21 & $39-160$ \\
\hline C-reactive protein, $\mathrm{mg} / \mathrm{dl}$ & 0.05 & 0.06 & 0.20 & 0.17 & $0.00-0.30$ \\
\hline $\mathrm{C}$ troponin $\mathrm{I}, \mathrm{ng} / \mathrm{ml}$ & 0.03 & NT & 0.13 & NT & $0.00-0.10$ \\
\hline Fibrinogen, mg/dl & 300 & NT & 382 & NT & $150-350$ \\
\hline Fasting blood sugar, $\mathrm{mg} / \mathrm{dl}$ & 243 & 250 & 295 & 222 & $60-100$ \\
\hline Hemoglobin A1c, $\%$ & 6.6 & 7.2 & 7.3 & NT & $3.9-5.9$ \\
\hline
\end{tabular}


been published as a consequence or side effect of gefitinib. Therefore, as part of pharmacovigilance, it is deemed important to report relevant findings on such incidences occurring during new therapies. The present patient suddenly complained of general fatigue under the administration of gefitinib and showed ST-T abnormalities on ECG. In the laboratory data, the elevation of creatinine kinase was not confirmed, although it was seen that lactic acid dehydrogenase was increased. Therefore, it is difficult to diagnose whether the present case is one of angina or infarction by these results only. However, the findings on the echocardiograph strongly supported myocardial infarction. The patient received aspirin to prevent relapse. In the platelet aggregation test, as aspirin seemed to work effectively, both ADP- and collagen-induced aggregations were suppressed. However, both the aggregations exhibited a tendency towards enhancement after the restart of gefitinib. These results of the aggregation test suggest that gefitinib may cause enhancement of the platelet function.

Recently, we reported that thromboxane (TX) $\mathrm{B}_{2}$ increased and prostaglandin (PG) 6-keto $\mathrm{F}_{2 \alpha} / \mathrm{TXB}_{2}$ ratio decreased in gefitinib-treated patients. However, these patients did not exhibit an increase of $\mathrm{PGE}_{2}$ or PG6-keto
$\mathrm{F}_{1 \alpha}$ [7]. $\mathrm{TXA}_{2}$ increases proliferation in the smooth muscle but $\mathrm{PGI}_{2}$ decreased the vascular smooth muscle cell proliferation $[8,9]$. Therefore, it was suggested that the vascular smooth muscle cell proliferation was induced in patients receiving gefitinib $[7,10]$. We also reported that accelerated platelet aggregation was observed in patients receiving gefitinib. These findings may be related with the two contrary effects of gefitinib $[7,10]$. The present case suggested the accentuation of platelet aggregability caused by gefitinib and also the possibility of inducing an episode of acute myocardial infarction due to the enhanced platelet aggregability.

Because of advanced age or smoking habits, patients with NSCLC may have some atherosclerotic risk factors. Moreover, platelet thrombosis tends to be more frequent than fibrin thrombosis in Japan. Gefitinib may accelerate thromboembolic diseases by TX/PG imbalance and platelet activation. We preliminarily employed aspirin in order to prevent thrombosis in some patients receiving gefitinib treatment. So far, we have not seen any case of thrombosis. We suggest that careful observation should be exercised in patients with a history of thromboembolic diseases and atherosclerotic risk factors when administering gefitinib.

\section{References}

1 Fukuoka M, Yano S, Giaccone G, Tamura T, Nakagawa K, Dauillard J-Y, et al: Multi-Institutional Randomized Phase II Trial of Gefitinib for Previously Treated Patients with Advanced Non-Small-Cell Lung Cancer. J Clin Oncol 2003;21:2237-2246.

2 Cappuzzo F, Gregorc V, Rossi E, Cancellieri A, Magrini E, Paties CT, et al: Gefitinib in pretreated non-small-cell lung cancer (NSCLC): analysis of efficacy and correlation with HER2 and epidermal growth factor receptor expression in locally advanced or metastatic NSCLC. J Clin Oncol 2003;21:2658-2663.

3 Lynch TJ, Bell DW, Sordella R, Gurubhagavatula $\mathrm{S}$, Okimoto RA, Brannigan $\mathrm{BW}$, et al: Activating mutations in the epidermal growth factor receptor underlying responsiveness of non-small-cell lung cancer to gefitinib. N Engl J Med 2004;350:2129-2139.
4 Okamoto I, Fujii K, Matsumoto M, Terasaki Y, Kihara N, Kohrogi H, et al: Diffuse alveolar damage after ZD1839 therapy in a patient with non-small cell lung cancer. Lung Cancer 2003; 40:339-342.

5 Ieki R, Saitoh E, Hashimoto E, Ohta T, Yuasa $\mathrm{K}$, Iguchi M, et al: Alveolar hemorrhage as a possible adverse drug reaction by gefitinib. Gan To Kagaku Ryoho 2003;30:977-980.

6 Raben D, Bianco C, Damiano V, Bianco R, Melisi D, Mignogna C, et al: Antitumor activity of ZD6126, a novel vascular-targeting agent, is enhanced when combined with ZD1839, an epidermal growth factor receptor tyrosine kinase inhibitor, and potentiates the effects of radiation in a human non-small cell lung cancer xenograft model. Mol Cancer Ther 2004;3:977-983.
7 Kanazawa S, Yamaguchi K, Kinoshita Y, Muramatsu M, Komiyama Y, Nomura S: Gefitinib affects functions of platelets and blood vessels via changes in the prostanoids balance. Clin Appl Thromb Hemost 2005, in press.

8 Murota SI, Morita I, Abe M: The effects of thromboxane $\mathrm{B}_{2}$ and 6-ketoprostaglandin $\mathrm{F}_{1 \alpha}$ on cultured fibroblast. Biochim Biophys Acta 1977;479:122-125.

9 Mene P, Abboud HE, Dunn MJ: Regulation of human mesangial cell growth in culture by thromboxane $\mathrm{A}_{2}$ and prostacyclin. Kidney Int 1990;38:232-239.

10 Kanazawa S, Muramatsu M, Kinoshita Y, Yamaguchi K, Nomura S: Gefitinib has the potential of activating cell immunity against malignant cells. J Clin Oncol 2005;23:38653866. 